\title{
Reseña de Prosperi, Adriano, La vocazione: storie di gesuiti tra cinquecento e seicento, Torino, Einaudi, 2016, 272 pp., ISBN 978-8-858422-55-7
}

\section{Julián Díez Torres}

University of North Carolina at Chapel Hill

EE.UU.

jdiez@email.unc.edu

[Hipogrifo, (issn: 2328-1308), 5.2, 2017, pp. 595-596]

Recibido: 02-05-2017 / Aceptado: 22-05-2017

DOI: http://dx.doi.org/10.13035/H.2017.05.02.34

Prolífico especialista en la historia cultural de la Contra-Reforma, Adriano Prosperi dedica su último libro a los relatos de vocación de jesuitas de fines del XVI e inicios del XVII. En el proemio, Prosperi confronta dos sentidos de la palabra jesuita: un tipo de persona de carne y hueso, y un estereotipo (el jesuitismo, la imagen del jesuita). A crear la dicotomía contribuyeron tanto los jesuitas, que se presentaban a sí mismos como un cuerpo de élite que actualizaba el espíritu de cruzada a través del ideal de misión, como sus enemigos, quienes acusaban a la Compañía de servir a España y al Papado, de complotistas y de hipócritas. En vez de limitarse a separar hechos y modelos, y opiniones y ciencia, Prosperi abarca en su enfoque las vidas de personas concretas y la imagen social de dichas vidas. Este marco se completa con una breve discusión de bibliografía reciente. De una parte, bibliografía sobre los jesuitas; y de otra, referencias a la práctica de la escritura autobiográfica como modo de control institucional en ambientes comunistas del XX. Las vidas jesuitas se sitúan así a la vez en relación a su entorno inmediato (dentro de la Compañía de Jesús) y en un marco más amplio (la Compañía entendida como institución social).

La fuente primaria del estudio es un corpus de autobiografías y vidas de jesuitas, escritas a fines del XVI e inicios del XVII a petición de las autoridades de la Compañía. En estos relatos la vida se entiende como una «aventura terrena dominada por la idea de un Dios que dejaba a los individuos el libre arbitrio pero los invitaba a la perfección» (p. XVIII). En realidad, más que ante vidas propiamente dichas estamos ante «historias de iniciación» (p. 241), ya que los relatos se estructuran en torno al tema de la vocación. El corpus estaba pensado para funcionar como una suerte de archivo de ejemplos para estímulo y coacción de futuros jesuitas, y futuros aspirantes a jesuitas. Prosperi contextualiza el corpus en varios niveles históricos: el espacio entre los hitos de las confesiones de san Agustín y Rousseau; la 
época del individualismo renacentista, el cual explicaría la atención a experiencias individuales frente al predominio de los arquetipos en los relatos de vidas piadosas medievales; y la respuesta católica de control vertical frente al énfasis protestante en la libertad de conciencia. La discusión se lleva a cabo en tres bloques. El primero, dedicado a las bases de la vocación en la religiosidad ignaciana, en los mecanismos de ingreso en la Compañía y en las prácticas historiográficas jesuitas. El segundo bloque se ocupa de la institución del colegio jesuita entendido como medio de captación y selección de neófitos; y la tercera parte analiza dos grandes tensiones que surgen en los relatos: el conflicto con las familias y la dicotomía entre casos de admiración y casos fallidos. Mientras las dos primeras partes se dividen en capítulos breves que acumulan información de diversos casos para reconstruir la religiosidad jesuita y el funcionamiento de los colegios, la tercera parte, más extensa, se centra en vidas particulares, considerando tanto los hechos narrados como la escritura de las mismas.

Prosperi abarca un panorama de escala verdaderamente europea, lo cual se debe no solo a la estructura de la Compañía sino también a la capacidad del propio Prosperi para discutir asuntos tan diversos como las leyes de pureza de sangre instauradas por los jesuitas a partir de 1593, la inserción de la Compañía en la nobleza italiana, las divisiones entre católicos durante las guerras de religión francesas o las disputas entre escuelas teológicas y filosóficas en centros educativos del área véneta. Prosperi también logra compaginar la experiencia de los neófitos (fomentada por la Compañía) con la perspectiva de las familias, las instituciones eclesiásticas y el poder político. Es de notar también que en el libro encontramos algunas figuras señeras del primer siglo jesuita. Algunas de ellas fueron protagonistas de relatos de vocación (Bellarmino, Gonzaga); otras fueron autores de los relatos (Rivadeneira, tal vez Possevino); y otras, agentes relacionados con la elaboración (Loyola, Xavier, Possevino). Sin embargo, como los protagonistas del corpus estudiado forman parte de las generaciones segunda y tercera de jesuitas, un grupo mucho más amplio que la primera generación, Prosperi dispone de suficiente material como para centrarse en la generalización socio-cultural en vez de en trayectorias biográficas.

En definitiva, este libro breve pero panorámico reconstruye de manera clara y entretenida la función de los relatos de vocación dentro del imaginario jesuita, así como el contexto social de dichos relatos. Ello hace del libro una útil introducción a la cultura contra-reformista europea desde el enfoque en la experiencia jesuita. Personalmente, me habría gustado saber si los casos estudiados constituyen una muestra representativa del corpus de las historias de vocación jesuita, cosa que se hubiera aclarado con una descripción más detallada del corpus. ¿Hay que asumir que el corpus carece de materiales no relativos a Italia, Francia y en menor medida Alemania, o existe base para futuros estudios sobre otros territorios como la península Ibérica y los territorios de la misión ultramarina? Una segunda pregunta que me hago es si sería posible rastrear ecos de estos relatos vocacionales en proyectos posteriores (por ejemplo, historiográficos e iconográficos) vinculados a la construcción de la memoria colectiva de la Compañía. 